\title{
Association of Killer Immunoglobulin-Like Receptor and Human Leukocyte Antigen Class I Ligand with Recurrent Abortion in Saudi Women
}

\author{
Lamjed Mansour, ${ }^{1}$ Afrah Alkhuriji, ${ }^{2}$ Zeneb Ahmed Babay, ${ }^{3}$ Sarah Alqadheeb, ${ }^{2}$ Fadwa Al-Khulaifi, ${ }^{2,4}$ \\ Razan Al-Talhi, ${ }^{2}$ and Suliman Alomar ${ }^{1}$
}

\begin{abstract}
Aims: This study was designed to determine whether genetic polymorphisms of the killer immunoglobulin-like receptor (KIR) and human leukocyte antigen class I (HLA-C) genes are associated with recurrent spontaneous abortion (RSA) in Saudi women.

Materials and Methods: Sixty-five healthy women with a history of RSA (three or more spontaneous abortions) and 65 healthy controls (with two or more healthy-born children) living in Riyadh were typed for 17 KIR genes and the $H L A-C 1$ and $H L A-C 2$ allotypes using polymerase chain reaction-sequence-specific primer methodology. Results: The frequencies of KIR2DS2 and KIR2DL5A were significantly lower among RSA women compared to healthy controls (odds ratio $[\mathrm{OR}]=0.17 ; p<0.001 ; \mathrm{OR}=0.16 ; p<0.001$, respectively). No association with maternal HLA-C genotypes was observed. Analysis of KIR-HLA-C combinations indicated a protective effect of KIR2DS2 with its cognate $H L A-C 1$ ligand in both homozygote or heterozygote combinations.

Conclusion: Our results demonstrate that the KIR genes of the B haplotype may play an important role in ensuring the success of pregnancy.
\end{abstract}

Keywords: KIR genotype, HLA-C polymorphism, pregnancy loss, Saudi Arabia

\section{Introduction}

$\mathbf{N}$ ATURAL KILLER (NK) CELLS are an important component of the innate immune response, and they are involved in adaptive immunity (Smyth et al., 2002). Their effector functions include cytolytic activity against target cells and secretion of an inflammatory and regulatory panel of cytokines (Guillerey et al., 2016). NK cells express a diverse family of receptors (Makrigiannis and Anderson, 2003). Prominent among these are the killer cell immunoglobulinlike receptor (KIR) family that includes members that recognize and interact with human leukocyte antigen class I (HLA).

A total of $17 K I R$ genes and pseudogenes have been identified and are clustered in chromosome $19 \mathrm{q} 13.4$ within the leukocyte receptor complex (Wende et al., 1999). The KIR gene complex exhibits substantial diversity that affects the presence or absence of individual KIR genes, forming the haplotype (Middleton and Gonzelez, 2010; Vendelbosch et al., 2015). Eight of these $17 \mathrm{Kir}$ genes encode inhibitory KIRs (2DL1, 2DL2, 2DL3, 2DL5A, 2DL5B 3DL1, 3DL2, and 3DL3), 7 encode activating KIRs (2DL4, 2DS1, 2DS2, 2DS3, 2DS4,
2DS5, 2DS5, and 3DS1), and 2 are pseudogenes (2DP1 and 3DP1) (Long et al., 1997; Middleton and Gonzelez, 2010).

Substantial allelic polymorphism has been reported for different KIR genes (Middleton et al., 2007). Many different haplotypes have been reported, depending on the occurrence of KIR genes in an individual. These haplotypes are classified into the A and B haplotypes. Group A haplotypes contain a fixed number of genes encoding inhibitory genes and only one activating gene (KIR2DS4). Group B haplotype have variable gene contents and different activating KIRs, and the group is characterized by the presence of the KIR $2 D L 2$, KIR2DS1, KIR2DS2, KIR2DS3, and KIR2DS5 genes (Uhrberg et al., 2002; Uhrberg, 2005).

The ability of NK cells to recognize and eliminate foreign cells mainly results from the interaction of their KIRs with major histocompatibility complex class I molecules (MHC-I) expressed on the surface of target cells. Although $>3000$ alleles of HLA-C have been reported, they are recognized by KIRs as two distinct groups, HLA-C1 and HLA-C2, which are distinguished by the amino acid dimorphism at position 80. Several genetic studies have reported strong associations

\footnotetext{
${ }^{1}$ Doping Research Chair, Zoology Department, College of Science, King Saud University, Riyadh, Saudi Arabia.

${ }^{2}$ Zoology Department, College of Science, King Saud University, Riyadh, Saudi Arabia.

${ }^{3}$ College of Medicine, King Khalid University Hospital, King Saud University, Riyadh, Saudi Arabia.

${ }^{4}$ Biology Department, College of Science, Imam Abdulrahman Bin Faisal University, Dammam, Saudi Arabia.
} 
of KIRs and their ligands with the outcome of large number of infectious, autoimmune, or cancer diseases (Khakoo, 2010). In the Saudi population, associations between KIRs and some cancer and autoimmune diseases have recently been reported (Xiong et al., 2013; Al Omar et al., 2015; Osman et al., 2016; Alomar et al., 2017).

Recurrent spontaneous abortion (RSA) is a component of the range of reproductive failure, defined as two or more consecutive pregnancy losses before the 20th week of gestation in women of reproductive age (Rai and Regan, 2006; Branch et al., 2010). RSA is considered an important complication during pregnancy and represents a common frustrating problem in gynecology (Jauniaux et al., 2006). RSA has been reported in 1-2\% of reproductive-aged women. The reasons for most cases of RSA (40-55\%) remain unexplained (Li et al., 2002; Van den Berg et al., 2014). Different epidemiological studies have considered RSA as a multifactorial problem (Ferrara et al., 1996; Daher et al., 2012). Different etiologic factors have been implicated in this problem, such as endocrine regulation, autoimmune reactions, psychological characteristics, thrombophilia, viral infections, environmental factors, and genetic background (Li et al., 2002; Quenby et al., 2005).

In fact, the immunologic relationship between the mother and fetus is determined by fetal antigens and the maternal immune system. The inadequate recognition of fetal antigens might result in failed pregnancy (Vince and Johnson, 1995; Christiansen, 1996). NK cells have been reported to constitute the predominant leukocyte population present in the endometrium at the time of implantation and in early pregnancy (Hiby et al., 2004; Moffett et al., 2004; Male et al., 2011). Different studies have demonstrated the crucial role that NK cells play in the success versus failure of pregnancy during the first weeks. In the fetal-maternal interface, activity of $\mathrm{NK}$ cells is regulated through the interaction of the maternal KIRs with the paternal HLA-C ligand, which is the only polymorphic MHC molecule expressed by the invasive extravillous trophoblast (Hiby et al., 2010a; Male et al., 2011). Thus, the polymorphisms that characterize the KIRs and HLA-C ligand may affect the pregnancy outcome and could explain in part the reported relationship between the occurrence of some pregnancy disorders, including RSA, pre-eclampsia, and defective placentation, and some KIR-HLA-C combinations in different populations (Varla-Leftherioti et al., 2003; Wang et al., 2007; Hong et al., 2008; Nowak et al., 2009; Hiby et al., 2010a; Chazara et al., 2011; Faridi and Agrawal, 2011; Ozturk et al., 2012; Babor et al., 2014; Moffett and Colucci, 2015; Colucci, 2017; Wilczynska et al., 2019). In this study, we report the results of our investigation of the association between the maternal KIR and HLA-C genes and the occurrence of RSA in Saudi women.

\section{Materials and Methods}

\section{Subjects}

For this study, peripheral blood samples were obtained from 65 unrelated Saudi women who had experienced at least three unexplained RSA and from 65 unrelated control Saudi women without a history of complications in at least two or more successful pregnancies and without a history of RSA, pre-eclampsia, ectopic pregnancy, or preterm delivery. Both the women with an RSA and the controls had visited King Khaled University Hospital in Riyadh, Kingdom of Saudi Arabia, between January 2010 and January 2011. The mean age was $34.67 \pm 7.75$ years (range: $18-48$ years) for the control group and $34.21 \pm 6.26$ years (range: 19-45 years) for the RSA group.

Routine examination at the medical research center was performed to exclude all known factors for abortion, including parental karyotypes, hormone levels, toxoplasmosis, cytomegalovirus, rubella, antiphospholipid antibodies, protein $\mathrm{C}$, protein $\mathrm{S}$, glucose level, hysteroscopy, hysterosalpingography, and sequential ultrasound when required. Only women with unexplained RSA after performing all the tests mentioned earlier were included in this study. Ethical approval was obtained from the medical ethics committee of King Khalid University Hospital and the ethics committee of King Saud University. All patients and controls gave informed consent and agreed to provide blood samples for a case-control study.

\section{Genomic DNA extraction and KIR and HLA-C typing}

Genomic DNA was extracted from peripheral blood using a DNeasy Blood \& Tissue Kit (Qiagen, Valencia, CA) according to the manufacturer's instructions. Genotyping of KIRs was performed using a KIR polymerase chain reaction (PCR)-sequence-specific primer commercial typing kit (Miltenyi Biotec, Inc., Cologne, Germany) according to the manufacturer's instructions. This kit consists of a panel of locus-specific oligonucleotide primers allowing individual amplification of 17 KIR genes (15 genes and 2 pseudogenes) and the common variants of 2DS4 (Fig. 1).

For HLA-C1 and HLA-C2 typing, the same primers were used as those reported by Tajik et al. (2010). For each reaction, PCR was performed as reported by Omar et al. (2016). All PCRs were run in a Techne thermocycler apparatus (Techne TC-Plus Satellite). The PCR products were analyzed

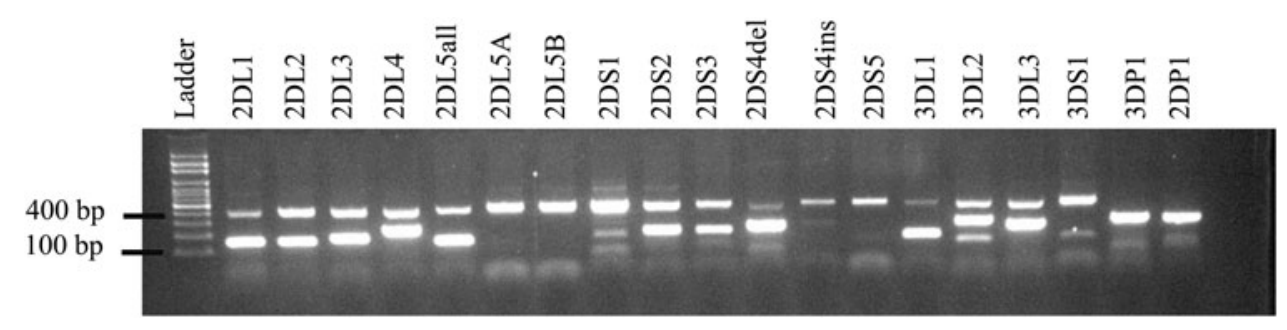

FIG. 1. Gel electrophoresis of KIR genotyping using PCR-SSP method. An internal positive control appears at 400 bp. The primers used for $2 D L 5$ all embrace two distinct, but closely related genes named $2 D L 5 A$ and $2 D L 5 B$. Some alleles of $2 D L 5 A$ are detected only with primers used for $2 D L 5$ all. In this typed sample, individual is considered $2 \mathrm{DL} 5 \mathrm{~A}^{+}$and $2 D L 5 B^{-}$. KIR, killer immunoglobulin-like receptor; PCR-SSP, polymerase chain reaction-sequence-specific primers. 
Table 1. Characterization of Recurrent Spontaneous Abortion and Control Healthy Women

\begin{tabular}{lccccc}
\hline Group & Sample size & Age & $\begin{array}{c}\text { No. of spontaneous abortions } \\
\text { (min-max) }\end{array}$ & $\begin{array}{c}\text { No. of children } \\
\text { (min-max) }\end{array}$ & $\begin{array}{c}\text { No. of pregnancies } \\
\text { (min-max) }\end{array}$ \\
\hline Control & 65 & $19-48$ & 0 & $2-8$ & $2-8$ \\
RSA & 65 & $18-45$ & $3-11$ & $0-7$ & $3-12$ \\
\hline
\end{tabular}

RSA, recurrent spontaneous abortion.

by electrophoresis in $2 \%$ agarose gels stained with ethidium bromide and visualized on a UV transilluminator using a gel documentation system (BioRad Gel225 Doc $^{\mathrm{TM}} \mathrm{XR}+$ ) to check for the presence or absence of gene-specific amplicons.

\section{Statistical analysis}

The frequency of each KIR, HLA-C ligand, and KIR-KIRligand combination in the patient and control groups was determined by direct counting. The data were analyzed with the statistical software SigmaPlot version 11. Differences between the two groups in the distribution of each KIR gene, HLA-C genotype, and KIR/HLA-C combination were analyzed using the $\chi^{2}$ and the two-tailed Fisher exact test with Bonferroni correction. Statistical significance was defined as $p \leq 0.05$. The magnitude of the effect was estimated by odds ratios (ORs) and their $95 \%$ confidence intervals.

\section{Results}

In this case-control study, we examined the distribution of KIR genotypes and the HLA-C alotype ligands among women with at least three unexplained RSAs and healthy women with at least two live births and without a history of RSA. Clinical and demographic characteristics of the RSA and control women are shown in Table 1 .

Table 2 presents the comparative distribution of the percentages of the 17 KIR genes for the two groups. In this study, all KIR genes were detected in both the RSA and control groups. The framework genes were present in all of the healthy control women. Among the RSA group, KIR $2 D L 4$ genes was absent in three individuals. $3 D L 3$ and $3 D P 1$ were recorded in all individuals. Significantly lower frequencies for the $2 D L 5 A, 2 D S 2$, and $2 D S 3$ genes were recorded in the RSA group compared with the control group $(\mathrm{OR}=0.16$, 0.178 , and 0.41 , respectively, with $p$-values $<0.05$ ). However, for the $2 D S 3$ gene, the difference between the two groups was no longer significant after Bonferroni correction. The frequency of $3 D S 1$ was also lower in the RSA group, but the difference did not reach statistical significance $(p=0.059)$. Regarding the $A A$ and $B B K I R$ haplotypes, no significant difference was observed in their distribution between the RSA and control groups. Moreover, no significant difference was

Table 2. Comparison of Killer Immunoglobulin-Like Receptor Gene Frequencies, Killer Immunoglobulin-Like Receptor Haplotypes, and Subhaplotypes Between Recurrent Spontaneous Abortion Women and Controls

\begin{tabular}{|c|c|c|c|c|c|}
\hline Genes & Patients $(\mathrm{n}=65), \mathrm{n}(\%)$ & Controls $(\mathrm{n}=65), \mathrm{n}(\%)$ & $\mathrm{p}$ & $O R$ & $95 \% C I$ \\
\hline 2DL1 & $53(81.5)$ & $53(81.5)$ & 1 & & \\
\hline 2DL3 & $54(83.1)$ & $53(81.5)$ & 0.99 & & \\
\hline 3DL1 & $59(90.8)$ & $64(98.5)$ & 0.11 & & \\
\hline 2DS4 & $61(94)$ & $60(92)$ & & & \\
\hline 2DS4ins & $28(43.1)$ & $35(53.8)$ & 0.29 & & \\
\hline 2DS4del & $52(80)$ & $54(83.1)$ & 0.82 & & \\
\hline 2DL2 & $36(55.4)$ & $47(72.3)$ & 0.067 & & \\
\hline 2DL5A & $14(21.5)$ & $41(63.1)$ & 0.0000027 & 0.16 & 0.073-0.349 \\
\hline 2DL5B & $33(50.8)$ & $34(52.3)$ & 0.99 & & \\
\hline 2DS1 & $16(24.6)$ & $22(33.8)$ & 0.335 & & \\
\hline 2DS2 & $23(35.4)$ & $49(75.4)$ & 0.0000078 & 0.178 & 0.083-0.382 \\
\hline $2 \mathrm{DS} 3$ & $24(36.9)$ & $38(58.5)$ & 0.022 & 0.41 & $0.20-0.84$ \\
\hline 2DS5 & $11(16.9)$ & $18(27.7)$ & 0.205 & & \\
\hline 3DS1 & $20(30.8)$ & $10(15.4)$ & 0.059 & & \\
\hline $\mathrm{AA}$ & $17(26.2)$ & $12(18.5)$ & 0.39 & & \\
\hline $\mathrm{BX}$ & $48(73.8)$ & $53(81.5)$ & & & \\
\hline Cent A & 44 & 44 & 1 & & \\
\hline Cent B & 13 & 20 & 0.22 & & \\
\hline Tel A & 59 & 60 & 0.99 & & \\
\hline Tel B & 6 & 8 & 0.77 & & \\
\hline \multicolumn{6}{|c|}{$2 \mathrm{DS} 2 / 2 \mathrm{DL} 5 \mathrm{~A}$} \\
\hline$+/+$ & 7 & 37 & $2.981^{-8}$ & 0.091 & $0.036-0.23$ \\
\hline$+1-$ & 16 & 13 & 0.67 & & \\
\hline$-1+$ & 7 & 5 & 0.76 & & \\
\hline$-1-$ & 21 & 5 & 0.00076 & 5.72 & 2.0-16.36 \\
\hline
\end{tabular}

Significant associations after Bonferroni correction are shown in bold. $\mathrm{CI}$, confidence interval; OR, odds ratio. 
Table 3. Relationship Between the Frequency of Activating Killer Immunoglobulin-Like Receptor Genes and Recurrent Spontaneous Abortion 3

\begin{tabular}{|c|c|c|c|c|c|}
\hline Number of activating KIR genes & 1 & 2 & 3 & 4 & 5 \\
\hline $\mathrm{RSA}, n(\%)$ & $5(7.7)$ & $14(21.54)$ & $10(15.4)$ & $6(9.2)$ & $3(4.6)$ \\
\hline Controls, $n(\%)$ & $11(16.9)$ & $17(21.15)$ & $10(15.4)$ & $8(12.3)$ & $8(12.3)$ \\
\hline$p$ & NS & NS & NS & NS & NS \\
\hline
\end{tabular}

KIR, killer immunoglobulin-like receptor.

observed in the frequencies of the two centromeric (Cen-A and $C e n-B)$ and telomeric (Tel-A and Tel-B) subhaplotypes (Table 2).

However, when considering the $2 D S 2$ and $2 D L 5 A$ genes, the occurrence of both genes in the $\mathrm{B}$ haplotypes contributed highly significantly to protection against RSA $(\mathrm{OR}=0.091$; $p<0.001)$. Inversely, the lack of both $2 D S 2$ and $2 L A 5 A$ was associated with an increase in the occurrence of spontaneous abortion within the Saudi population $(\mathrm{OR}=5.72 ; p=0.003)$. Different comparisons were performed for the distribution of the number of activating genes between the RSA group and control group, and we did not observe differences between the groups in the study population (Table 3 ). However, the presence of $2 D S 2$ conferred significant protection, regardless of the number of activating genes.

The frequencies of the $H L A-C 1$ and $H L A-C 2$ allotypes and genotypes were not different between the RSA group and healthy control group (Table 4).

The results of the analysis of the combined association of the KIR genes and HLA-C ligand with RSA are reported in Table 5. The $2 D L 1$ and $2 D S 2$ genes were found to be associated for some combinations with the $H L A-C$ ligand. Thus, a protective effect was observed for $2 D L 1$ in the absence of its $C 2$ ligand $(\mathrm{OR}=0.085, p=0.008)$. However, $2 D S 2$ exhibited a protective effect when associated with its $H L A-C 1$ ligand in the homozygote $(\mathrm{OR}=0.27, p=0.028)$ and heterozygote (HLA-C1C2) forms $(\mathrm{OR}=0.38, p=0.03)$. The distribution of $2 D L 2 / 3$ and the HLA-C1 ligand did not show any statistically significant difference.

\section{Discussion}

This study is the first investigation on the association between KIR gene polymorphism and recurrent abortion in Arabian ethnic group. We confirm, through these results, the relationship between some individual KIRs and some of its combinations with the HLA-C maternal ligand and the success versus failure of pregnancy in a Saudi population. We showed herein the frequent appearance of the three KIR

Table 4. Frequencies of the Killer IMMUNOGLOBULIN-LiKE RECEPTOR LIGAND C1/C2 in Recurrent Spontaneous Abortion Women and Healthy Control Groups

\begin{tabular}{lccc}
\hline Gene/genotype & Patients, n (\%) & Controls, $\mathrm{n}(\%)$ & $\mathrm{p}$ \\
\hline C1C1 & $19(29.23)$ & $17(27.7)$ & $\mathrm{NS}$ \\
C2C2 & $11(16.9)$ & $17(26.2)$ & $\mathrm{NS}$ \\
C1C2 & $35(53.84)$ & $31(47.7)$ & NS \\
C1 & $54(83.07)$ & $48(73.8)$ & NS \\
C2 & $46(70.8)$ & $48(73.8)$ & NS \\
\hline
\end{tabular}

genes, $2 D L 5 A, 2 D S 2$, and $2 D S 3$, among the healthy control group compared with the RSA group. The highest, and significant, association with protection against failure of pregnancy was observed with the $2 D L 5 A$ and $2 D S 2$ genes. These two genes are considered to belong to the $\mathrm{B}$ haplotype and have different positions in the KIR B haplotypes. The $2 D L 5 A$ gene has a telomeric position, whereas $2 D S 2$ is positioned at a centromeric region. Interestingly, the $2 \mathrm{DS} 2$ molecule interacts with the $\mathrm{C} 1$ ligand. The presence of both genes correlates with reduced RSA (10-fold lower rate of occurrence) possibly by supporting successful pregnancy. Inversely, a lack of both genes is associated with a more than fivefold higher rate of RSA occurrence. This result indicates a possible dose effect of the KIR genes on the occurrence of RSA.

It is worthy to notice that the biological significance of KIRs in vivo depends on whether these receptors are present in individuals simultaneously with their ligands. A combinatory analysis confirmed that the KIR2DS2 gene has a strong protective effect with its specific $H L A-C 1$ allele both in homozygote and heterozygote forms. Moreover, this protection was no longer effective in the absence of its ligand. In this context of the KIR-HLA-C interaction effect, the activating KIR2DL1 exhibited a protective effect when its HLA-C2 ligand was missing.

Until now, few studies had been performed on the association between KIRs and spontaneous abortion. Except for the study by Witt et al. (2004), which did not report any significant association of KIR genes or genotypes with spontaneous abortion in 51 Brazilian Caucasian women, most of the studies reported conflicting results. A protective association of some activating KIRs of the telomeric B haplotype region, particularly $2 D S 1$ as well as $3 D S 1,2 D S 5$, and 2DL5, with RSA was reported in an English Caucasian population composed of 95 RSA cases and 269 controls (Moffett and Colucci, 2015). Moreover, in the same study population, the AA haplotype was found to be positively associated with recurrent miscarriage (Hiby et al., 2010b; Moffett and Colucci, 2015). Faridi et al. (2009) reported a protective effect of the KIR AA haplotype and inhibitory genes in an Asian Indian population composed of 205 women with a history of RSA and 224 controls belonging to different ethnic groups. In this study, the authors reported a probable protective effect of the inhibitory genes $2 D L 2$ and $3 D L 1$ and a predisposition effect of the activating genes $2 D S 2$ and $2 D S 3$. Other conflicting results were also reported by Hong et al. (2008), showing an association of 2DL2 (a B haplotype gene) with RSA in a very small group of Chinese women composed of 16 women with a history of RSA and 24 controls and without correction of the results. This result was not confirmed by another Chinese study that included higher numbers of individuals (73 RSA couples and 68 control couples), as it showed an increase in the activating KIR genes 
Table 5. Distribution of the Frequencies of Killer Immunoglobulin-Like Receptor Genes in Presence and Absence of Their C1C2 Ligand Between

Recurrent Spontaneous Abortion Patients and Controls

\begin{tabular}{|c|c|c|c|c|c|c|c|}
\hline \multirow[b]{2}{*}{ KIR/ligand } & \multicolumn{2}{|c|}{ Patients } & \multicolumn{2}{|c|}{ Controls } & \multirow[b]{2}{*}{$\mathrm{p}$} & \multirow[b]{2}{*}{$O R$} & \multirow[b]{2}{*}{$C I$} \\
\hline & $\mathrm{n}$ & $\%$ & $\mathrm{n}$ & $\%$ & & & \\
\hline $2 \mathrm{DL} 2^{+} \mathrm{C} 1^{+}$ & 26 & 40 & 26 & 40 & NS & & \\
\hline $2 \mathrm{DL} 2^{+} \mathrm{C} 1 \mathrm{C} 1^{+}$ & 6 & 9.23 & 6 & 9.23 & NS & & \\
\hline $2 \mathrm{DL}^{+} \mathrm{C} 1 \mathrm{C} 2^{+}$ & 21 & 32.3 & 21 & 32.3 & NS & & \\
\hline $2 \mathrm{DL} 2^{+} \mathrm{Cl}^{-}$ & 9 & 13.84 & 11 & 16.9 & NS & & \\
\hline $2 \mathrm{DL}^{+} \mathrm{Cl}^{+}$ & 46 & 70.7 & 37 & 56.9 & NS & & \\
\hline $2 \mathrm{DL}^{+}{ }^{+} \mathrm{ClC}^{+}$ & 18 & 27.7 & 15 & 23.1 & NS & & \\
\hline $2 \mathrm{DL}^{+}{ }^{+} \mathrm{C} 1 \mathrm{C} 2^{+}$ & 28 & 43.07 & 26 & 40 & NS & & \\
\hline $2 \mathrm{DL}^{+} \mathrm{Cl}^{-}$ & 8 & 12.3 & 11 & 16.9 & NS & & \\
\hline $2 \mathrm{DL} 2 / 3^{+} \mathrm{C1}^{+}$ & 20 & 30.76 & 31 & 47.7 & NS & & \\
\hline $2 \mathrm{DL} 2 / 3^{+} \mathrm{C} 1 \mathrm{C} 1^{+}$ & 6 & 9.23 & 14 & 21.53 & NS & & \\
\hline $2 \mathrm{DL} 2 / 3^{+} \mathrm{C} 1 \mathrm{C} 2^{+}$ & 14 & 21.53 & 17 & 26.2 & NS & & \\
\hline $2 \mathrm{DL} 2 / 3^{+} \mathrm{C} 1^{-}$ & 6 & 9.23 & 7 & 10.8 & NS & & \\
\hline $2 \mathrm{DL} 1^{+} \mathrm{C}^{+}$ & 36 & 55.4 & 43 & 66.2 & NS & & \\
\hline $2 \mathrm{DL}^{+}{ }^{+} \mathrm{C} 2 \mathrm{C} 2^{+}$ & 10 & 15.4 & 16 & 24.6 & NS & & \\
\hline $2 \mathrm{DL}^{+}{ }^{+} \mathrm{C} 1 \mathrm{C} 2^{+}$ & 26 & 40 & 22 & 33.84 & NS & & \\
\hline $2 \mathrm{DL1} 1^{+} \mathrm{C2}^{-}$ & 1 & 1.54 & 10 & 15.4 & 0.008 & 0.085 & $0.010-0.692$ \\
\hline $\mathrm{DDS2}^{+} \mathrm{C1}^{+}$ & 17 & 26.2 & 39 & 60 & 0.00017 & 0.23 & $0.11-0.49$ \\
\hline $\mathrm{DDS2}^{+} \mathrm{ClC1}^{+}$ & 5 & 7.7 & 15 & 23.1 & 0.028 & 0.27 & 0.094-0.817 \\
\hline $2 \mathrm{DS2}^{+} \mathrm{C1C2}^{+}$ & 12 & 18.5 & 24 & 36.9 & 0.03 & 0.38 & $0.17-0.86$ \\
\hline $2 \mathrm{DS}^{+} \mathrm{C}^{-}$ & 6 & 9.23 & 10 & 15.4 & NS & & \\
\hline $2 \mathrm{DS} 1^{+} \mathrm{C} 2^{+}$ & 12 & 18.5 & 15 & 23.1 & NS & & \\
\hline $2 \mathrm{DS} 1^{+} \mathrm{C} 2 \mathrm{C} 2$ & 4 & 6.2 & 5 & 7.7 & NS & & \\
\hline $2 \mathrm{DS} 1^{+} \mathrm{C} 1 \mathrm{C} 2$ & 8 & 12.3 & 10 & 15.4 & NS & & \\
\hline $2 \mathrm{DS} 1^{+} \mathrm{C} 2^{-}$ & 4 & 6.2 & 7 & 10.8 & NS & & \\
\hline $2 \mathrm{DL}^{+} / 2 \mathrm{DS} 2^{+} / \mathrm{C}^{+}$ & 11 & 16.9 & 34 & 52.3 & NS & & \\
\hline $2 \mathrm{DL}^{+} / 2 \mathrm{DS} 2^{-} / \mathrm{C} 1^{+}$ & 10 & 15.4 & 10 & 15.4 & NS & & \\
\hline $2 \mathrm{DL} 2^{-} / 2 \mathrm{DS} 2^{+} / \mathrm{C}^{+}$ & 1 & 1.54 & 2 & 3.1 & NS & & \\
\hline $2 \mathrm{DL}^{+} / 2 \mathrm{DS}^{+} / \mathrm{C}^{-}$ & 3 & 4.6 & 4 & 6.2 & NS & & \\
\hline $2 \mathrm{DL} 2^{-} / 2 \mathrm{DS} 2^{-} / \mathrm{C}^{+}$ & 13 & 20 & 7 & 10.8 & NS & & \\
\hline
\end{tabular}

Significant associations after Bonferroni correction are shown in bold.

2DS1 and 2DS5 and an association of RSA with higher numbers of activating KIRs (Wang et al., 2007). Similarly, in 68 Brazilian Caucasian RSA patients, genotypes with five or six activating $K I R$ genes were significantly more frequent than in 68 controls (Vargas et al., 2009). Although no single $K I R$ gene reached significance for its frequency distribution in this study Varla-Leftherioti et al. (2003) reported a lack of appropriate inhibitory KIRs in RM women from Greece in a study that included 15 patients with a history of RSA. Likewise, the AA genotype was reported to have a high frequency compared with a low frequency of B genotypes in 40 Anatolian women of European descent with a history of RSA who settled on the Mediterranean coast (Ozturk et al., 2012). More recently, a study conducted by Ay et al. (2019) in a women population from Turkey having unexplained recurrent pregnancy loss (URPL: before or after birth) reported strong positive association of eight $K I R$ genes $(2 D L 1,2 D L 2,2 D L 3$, $2 D L 4,2 D S 1,2 D S 2,2 D S 4$, and 2DS5) with loss of pregnancy. Surprisingly in this study, the framework 2DL4 gene is not frequent in control group (21.4\%) versus case group (68\%), which was never reported in any studied population. In this study, authors did not consider the 2DL5 gene and failed to amplify the 2DS3 genes in both case and groups (Ay et al., 2019). These conflicting results are a subject of controversy and debate regarding the method of typing and the matching of patients and controls according to ethnic origin as well as exclusion criteria/inclusion in the choice of patients and controls (Faridi and Agrawal, 2009; Hiby et al., 2010b). Indeed, in almost all studies, the patients and controls were not selected according to the same criteria regarding the number of spontaneous abortions in the patient group and the number of pregnancies in the control group.

Regarding the maternal HLA-C1 and HLA-C2 groups, as reported in almost all previous studies, we did not observe significant differences between the RSA and control groups. However, controversial associations have been reported between paternal $\mathrm{C} 1$ and $\mathrm{C} 2$ allotypes of the fetus and recurrent abortion in some studied populations. The paternal C2 allotype, which is the cognate ligand of the 2DS1 gene, but not the maternal $\mathrm{C} 2$ allotype, was positively associated with recurrent abortion in English Caucasian affected women, especially when the mother carried the A haplotype (Moffett and Colucci, 2015). In an Indian population, in contrast to our results and those reported by Faridi and Agrawal (2011) and Hiby et al. (2010b) reported that KIR2DL1 was significantly higher in control couples when both parents were homozygous for $H L A-C 2$ and that the activating KIR2DS 2 was significantly higher in patients when both parents were homozygous for HLA C1. These authors hypothesized that RSA was related to excessive activation or the lack of appropriate inhibition of NK cells. However, recent functional analyses have provided evidence that uterine NK ( $\mathrm{uNK}$ ) cells are 
phenotypically and functionally different from peripheral NK (pNK) cells (Nishikawa et al., 1991; Park et al., 2010). Thus, it is obvious that the primary function of the immune system and decidual NK cells in pregnancy is not killing but angiogenesis and ensuring good vascularization of the placenta by allowing good blood flow, which is necessary to maintain placental growth (Xie et al., 2005; Arcuri et al., 2006; Kumar and Medhi, 2008; Hofmann et al., 2014; Fraser et al., 2015). These uNK are characterized by their high capacity to produce a wide range of growth factors, cytokines, and chemokines, which are beneficial for trophoblast migration and the trophoblast-mediated remodeling of uterine vessels. Recently, functional studies have shown the important role played by activating genes such as $2 D S 1$ and $2 D S 4$ in the success of pregnancy. These two genes as well as the inhibitory $2 D L 1$ gene were reported to be overexpressed in decidual NK cells at the beginning of pregnancy (Xiong et al., 2013). In the absence of KIR2DS1, the insufficient activation of decidual NK cells results in poor trophoblast invasion, placental stress, and growth restriction of the fetus (Chazara et al., 2011; Xiong et al., 2013).

These functional studies support the fact that signals delivered by the inhibitory or the activating KIRs in decidua are not always relatively cytotoxic as they are in their action against foreign transplants but also induce the secretion of cytokines and chemokines necessary for the development of the placenta and fetus. Although Xiong et al. (2013) reported a lack of expression of KIR2DS1 in uNK cells, no study has been performed on the KIR2DS2 gene. In conclusion, we believe that further investigations involving subjects with different ethnic origins would aid in understanding this relationship between the uNk phenotype and the evolution of gestations by taking into account genetic diversity.

\section{Author Disclosure Statement}

No competing financial interests exist.

\section{Funding Information}

This study was financed by the Researchers Supporting Project number (RSP-2019/35), King Saud University, Riyadh, Saudi Arabia.

\section{References}

Al Omar SY, Mansour L, Dar JA, et al. (2015) The relationship between killer cell immunoglobulin-like receptors and HLAC polymorphisms in colorectal cancer in a Saudi population. Genet Test Mol Biomarkers 19:617-622.

Alomar SY, Alkhuriji A, Trayhyrn P, et al. (2017) Association of the genetic diversity of killer cell immunoglobulin-like receptor genes and HLA-C ligand in Saudi women with breast cancer. Immunogenetics 69:69-76.

Arcuri F, Cintorino M, Carducci A, et al. (2006) Human decidual natural killer cells as a source and target of macrophage migration inhibitory factor. Reproduction 131:175-182.

Ay ME, Ay OI, Cayan FE, et al. (2019) Genetic predisposition to unexplained recurrent pregnancy loss: killer cell immunoglobulinlike receptor gene polymorphisms as potential biomarkers. Genet Test Mol Biomarkers 23:57-65.

Babor F, Manser AR, Fischer JC, et al. (2014) KIR ligand C2 is associated with increased susceptibility to childhood ALL and confers an elevated risk for late relapse. Blood 124:2248-2251.
Branch DW, Gibson M, Silver RM (2010) Recurrent miscarriage. N Engl J Med 363:1740-1747.

Chazara O, Xiong S, Moffett A (2011) Maternal KIR and fetal HLA-C: a fine balance. J Leukoc Biol 90:703-716.

Christiansen OB (1996) A fresh look at the causes and treatments of recurrent miscarriage, especially its immunological aspects. Hum Reprod Update 2:271-293.

Colucci F (2017) The role of KIR and HLA interactions in pregnancy complications. Immunogenetics 69:557-565.

Daher S, Mattar R, Gueuvoghlanian-Silva BY, Torloni MR (2012) Genetic polymorphisms and recurrent spontaneous abortions: an overview of current knowledge. Am J Reprod Immunol 67:341-347.

Faridi RM, Agrawal S (2009) Reply: influence of activating and inhibiting killer immunoglobulin-like receptors on predisposition to recurrent miscarriages. Hum Reprod 24:2383-2384.

Faridi RM, Agrawal S (2011) Killer immunoglobulin-like receptors (KIRs) and HLA-C allorecognition patterns implicative of dominant activation of natural killer cells contribute to recurrent miscarriages. Hum Reprod 26:491-497.

Faridi RM, Das V, Tripthi G, et al. (2009) Influence of activating and inhibitory killer immunoglobulin-like receptors on predisposition to recurrent miscarriages. Hum Reprod 24: 1758-1764.

Ferrara N, Carver-Moore K, Chen H, Dowd M (1996) Heterozygous embryonic lethality induced by targeted inactivation of the VEGF gene. Nature 380:439.

Fraser R, Whitley GS, Thilaganathan B, Cartwright JE (2015) Decidual natural killer cells regulate vessel stability: implications for impaired spiral artery remodelling. J Reprod Immunol 110:54-60.

Guillerey C, Huntington ND, Smyth MJ (2016) Targeting natural killer cells in cancer immunotherapy. Nat Immunol 17: 1025-1036.

Hiby SE, Apps R, Sharkey AM, et al. (2010a) Maternal activating KIRs protect against human reproductive failure mediated by fetal HLA-C2. J Clin Invest 120:4102-4110.

Hiby SE, Ashrafian-Bonab M, Farrell L, et al. (2010b) Distribution of killer cell immunoglobulin-like receptors (KIR) and their HLA-C ligands in two Iranian populations. Immunogenetics 62:65-73.

Hiby SE, Walker JJ, O'Shaughnessy KM, et al. (2004) Combinations of maternal KIR and fetal HLA-C genes influence the risk of preeclampsia and reproductive success. J Exp Med 200:957-965.

Hofmann AP, Gerber SA, Croy BA (2014) Uterine natural killer cells pace early development of mouse decidua basalis. Mol Hum Reprod 20:66-76.

Hong Y, Wang X, Lu P, et al. (2008) Killer immunoglobulinlike receptor repertoire on uterine natural killer cell subsets in women with recurrent spontaneous abortions. Eur J Obstet Gynecol Reprod Biol 140:218-223.

Jauniaux E, Farquharson RG, Christiansen OB, Exalto N (2006) Evidence-based guidelines for the investigation and medical treatment of recurrent miscarriage. Hum Reprod 21:2216-2222.

Khakoo SI (2010) The role of KIR in disease. In: Zimmer J (ed). Natural Killer Cells: At the Forefront of Modern Immunology. Springer Berlin Heidelberg, Berlin, Heidelberg, pp 275-298.

Kumar V, Medhi B (2008) Emerging role of uterine natural killer cells in establishing pregnancy. Iran J Immunol 5:71-81.

Li TC, Makris M, Tomsu M, et al. (2002) Recurrent miscarriage: aetiology, management and prognosis. Hum Reprod Update 8:463-481. 
Long EO, Burshtyn DN, Clark WP, et al. (1997) Killer cell inhibitory receptors: diversity, specificity, and function. Immunol Rev 155:135-144.

Makrigiannis AP, Anderson SK (2003) Regulation of natural killer cell function. Cancer Biol Ther 2:610-616.

Male V, Sharkey A, Masters L, et al. (2011) The effect of pregnancy on the uterine NK cell KIR repertoire. Eur J Immunol 41:3017-3027.

Middleton D, Gonzelez F (2010) The extensive polymorphism of KIR genes. Immunology 129:8-19.

Middleton D, Meenagh A, Gourraud PA (2007) KIR haplotype content at the allele level in 77 Northern Irish families. Immunogenetics 59:145-158.

Moffett A, Colucci F (2015) Co-evolution of NK receptors and HLA ligands in humans is driven by reproduction. Immunol Rev 267:283-297.

Moffett A, Regan L, Braude P (2004) Natural killer cells, miscarriage, and infertility. BMJ 329:1283-1285.

Nishikawa K, Saito S, Morii T, et al. (1991) Accumulation of CD16-CD56+ natural killer cells with high affinity interleukin 2 receptors in human early pregnancy decidua. Int Immunol 3:743-750.

Nowak I, Malinowski A, Tchorzewski H, et al. (2009) Frequencies of killer immunoglobulin-like receptor genotypes influence susceptibility to spontaneous abortion. J Appl Genet 50:391-398.

Omar SY, Alkuriji A, Alwasel S, et al. (2016) Genotypic diversity of the Killer Cell Immunoglobulin-like Receptors (KIR) and their HLA class I Ligands in a Saudi population. Genet Mol Biol 39:14-23.

Osman AE, Eltayeb EN, Mubasher M, et al. (2016) Investigation of activating and inhibitory killer cell immunoglobulinlike receptors and their putative ligands in type 1 diabetes (T1D). Hum Immunol 77:110-114.

Ozturk OG, Sahin G, Karacor ED, Kucukgoz U (2012) Evaluation of KIR genes in recurrent miscarriage. J Assist Reprod Genet 29:933-938.

Park DW, Lee HJ, Park CW, et al. (2010) Peripheral blood NK cells reflect changes in decidual NK cells in women with recurrent miscarriages. Am J Reprod Immunol 63:173-180.

Quenby S, Farquharson RG, Dawood F, et al. (2005) Recurrent miscarriage and long-term thrombosis risk: a case-control study. Hum Reprod 20:1729-1732.

Rai R, Regan L (2006) Recurrent miscarriage. Lancet 368:601611.

Smyth MJ, Hayakawa Y, Takeda K, Yagita H (2002) New aspects of natural-killer-cell surveillance and therapy of cancer. Nat Rev Cancer 2:850-861.

Tajik N, Shahsavar F, Nasiri M, Radjabzadeh MF (2010) Compound KIR-HLA genotype analyses in the Iranian population by a novel PCR-SSP assay. Int $\mathrm{J}$ Immunogenet 37 : $159-168$.

Uhrberg M (2005) The KIR gene family: life in the fast lane of evolution. Eur J Immunol 35:10-15.

Uhrberg M, Parham P, Wernet P (2002) Definition of gene content for nine common group B haplotypes of the Caucasoid population: KIR haplotypes contain between seven and eleven KIR genes. Immunogenetics 54:221-229.

Van den Berg MM, Vissenberg R, Goddijn M (2014) Recurrent miscarriage clinics. Obstet Gynecol Clin North Am 41:145155.
Vargas RG, Bompeixe EP, Franca PP, et al. (2009) Activating killer cell immunoglobulin-like receptor genes' association with recurrent miscarriage. Am J Reprod Immunol 62:34-43.

Varla-Leftherioti M, Spyropoulou-Vlachou M, Niokou D, et al. (2003) Natural killer (NK) cell receptors' repertoire in couples with recurrent spontaneous abortions. Am J Reprod Immunol 49:183-191.

Vendelbosch S, de Boer M, van Leeuwen K, et al. (2015) Novel insights in the genomic organization and hotspots of recombination in the human KIR locus through analysis of intergenic regions. Genes Immun 16:103-111.

Vince GS, Johnson PM (1995) Materno-fetal immunobiology in normal pregnancy and its possible failure in recurrent spontaneous abortion? Hum Reprod 10(Suppl 2):107-113.

Wang S, Zhao YR, Jiao YL, et al. (2007) Increased activating killer immunoglobulin-like receptor genes and decreased specific HLA-C alleles in couples with recurrent spontaneous abortion. Biochem Biophys Res Commun 360:696-701.

Wende H, Colonna M, Ziegler A, Volz A (1999) Organization of the leukocyte receptor cluster (LRC) on human chromosome 19q13.4. Mamm Genome 10:154-160.

Wilczynska K, Wisniewski A, Malinowski A, et al. (2019) ERAP, KIR and HLA-C gene interaction in susceptibility to recurrent spontaneous abortion in the Polish population. Hum Immunol 80:344-348.

Witt C, Goodridge J, Gerbase-Delima M, et al. (2004) Maternal KIR repertoire is not associated with recurrent spontaneous abortion. Hum Reprod 19:2653-2657.

Xie X, He H, Colonna M, et al. (2005) Pathways participating in activation of mouse uterine natural killer cells during pregnancy. Biol Reprod 73:510-518.

Xiong S, Sharkey AM, Kennedy PR, et al. (2013) Maternal uterine NK cell-activating receptor KIR2DS1 enhances placentation. J Clin Invest 123:4264-4272.

Address correspondence to: Suliman Alomar, PhD

Doping Research Chair Zoology Department

College of Science

King Saud University

P.O. Box: 2455

Riyadh 11451

Saudi Arabia

E-mail: syalomar@ksu.edu.sa

Lamjed Mansour, PhD

Doping Research Chair Zoology Department

College of Sciences

King Saud University

P.O. Box: 2455

Riyadh 11451

Saudi Arabia

E-mail: lamjed.mansour@gmail.com; lmansour@ksu.edu.sa 